Industrial Research, 1957) is the fifth volume to be issued in this series and follows the arrangement of earlier volumes. Entries are made alphabetically by university under the name of the university department, except that all chemistry entries are placed under the one general heading chemistry (inorganic, organic and physical), and entomology entries may be found under zoology when entomological work is done in the Department of Zoology. The information is given in the language in which it was received from the universities, but headings and subheadings are in English only and an English translation is given of the subject of each research reported in Afrikaans.

\section{Zoological Society of India}

AN Indian Zoological Society was founded in 1939 but, due to the death of the convenor of its committee of formation and the outbreak of war, it fell into abeyance. It was reconstituted, however, under its present title of the Zoological Society of India in 1947. The first Year Book of the Society for the year 1956-57 has now been published (pp. ii $+48+$ 2 plates. Calcutta: Zoological Society of India, 1957. Rs. 2), corresponding in format with the Society's Journal, of which nine annual volumes have now appeared. The contents of the Year Book, reports of officers, rules, list of members, etc., are those customarily found in such publications. It also includes photographs of the two gold medals awarded by the Society and of their recipients, Dr. M. L. Roonwal and Dr. H. R. Mehra. The Society is undertaking to continue the well-known series of Indian Zoological Memoirs initiated by the late Prof. K. N. Bahl, of which the ninth, on Dasyatis, the Indian sting ray, by Dr. M. Chaudy, is almost ready for distribution.

\section{Lady Tata Memorial Awards for 1958-59}

ThE Trustees of the Lady Tata Memorial Fund, on the recommendation of the (European) Scientific Advisory Committee, have made the following awards for research on leukæmia and allied diseases in the academic year beginning October 1, 1958: Grants for research expenses (renewals), Dr. M. Seligmann (Institut Pasteur, Paris) ; Dr. M. Simonsen (Institute of Pathological Anatomy, Copenhagen); Prof. B. Thorell (Karolinska Institute, Stockholm); Dr. M. Bessis (Centre National de Transfusion Sanguine, Paris); Prof. G. Klein (Karolinska Institute, Stockholm); Dr. Jan Ponten (Patologiske Institutet, Upsala), new award. Scholarships, Dr. A. J. Therkelsen (Institute of General Pathology, Aarhus), renewal ; Dr. Aiyappan Pillai (Centre de Microscopie Electronique, Lausanne), new award.

\section{Announcements}

Srr Chartegs Goodeve, director of the British Iron and Steel Research Association, has been elected Master of the Salters' Company.

Dr. Gragory Prarcus has been awarded the Oliver Bird Trust Prize for 1957, specifically for a paper entitled "Fertility Control with Oral Medication", and generally for the contributions made under his direction to the study of fertility and its control in the Worcester Foundation for Experimental Biology, Shrewsbury, Massachusetts.

Ar the annual general meeting of the Royal Statistical Society on June 18, Sir Harry Campion was re-elected president for the ensuing year. Mr. B. Benjamin, Miss J. I. Douglas and Dr. P. Armitage were elected honorary secretaries and Mr. R. F. Fowler was re-elected honorary treasurer. Mr. R. F. George retires as an honorary secretary after completing ten years of office. The Guy Medal in silver was awarded to Prof. G. A. Barnard. The Frances Wood Memorial Prize was awarded to Mr. David Hewitt.

THE International Commission on Zoological Nomenclature has now secured new office accommodation (see Nature, 181, 1308; 1958), and all correspondence relating to the work of the Commission in connexion with the coming International Congress of Zoology should in future be addressed to Mr. R. V. Melville, Assistant Secretary, International Commission on Zoological Nomenclature, 119 Parkway, Gloucester Gate, London, N.W.1.

The seventh International Symposium on Combustion, organized by the Combustion Institute in collaboration with the Institute of Fuel, is to be held in Oxford during August 27-September 3. Full details may be obtained from the Institute of Fuel, 18 Devonshire Street, Portland Place, London, W.1.

A summer school on "The Science and Art of Health Education", arranged by the Central Council for Health Education, is to be held at Bishop Otter College, Chichester, during August 19-29. The school is intended for medical officers of health, physicians, teachers, public health inspectors, nurses and welfare officers and all whose work involves health teaching. Further information can be obtained from The Medical Director, Central Council for Health Education, Tavistock House, Tavistock Square, London, W.C.1.

The College of Technology, Birmingham, is again offering a full-time course of three weeks duration on "Statistical Quality Control and Acceptance Sampling" commencing on September 8. While the course is primarily intended as an introduction to the subject, nevertheless it provides the basic training necessary for quality control engineers. Further information can be obtained from the Registrar, College of Technology, Birmingham, 4.

A TWO-DAY meeting of the Royal Meteorological Society, preceded by a dinner and reception, will be held in the Museum Building, Trinity College, Dublin, during June 25-27, by invitation of the Department of Meteorology and Geophysics, School of Cosmic Physics, Dublin. The meeting, which is open without fee to non-members, is to be devoted to discussions on atmospheric aerosols and aeronautical meteorology on June 25 and 26 respectively. Further details may be obtained from the Assistant Secretary, Royal Meteorological Society, 49 Cromwell Road, London, S.W.7.

ERratum. In the article on "Role of Plant Hormones in Algal Metabolism and Ecology" by Dr. Joyce A. Bentley in Nature of May 31, the sentence on p. 1500 beginning on line 16 should read: "Similarly, the same two peaks occur in Oscillatoria acid and saponified fractions, together with some indole colour reactions, in Anat:aena medium acid fraction and aqueous non-saponified (first zone displaced nearer the starting line), and filtered sea-water acid fraction". 